\title{
COMPARISON OF THE EFFECTS OF 6 WEEKS OF SQUAT TRAINING WITH A PLYOMETRIC TRAINING PROGRAMME UPON DIFFERENT PHYSICAL PERFORMANCE TESTS IN ADOLESCENT TEAM HANDBALL PLAYERS
}

\author{
Roland van den Tillaar, Lars Waade, Truls Roaas \\ Department of Sports Science of Nord Trøndelag University College, \\ Levanger, Norway
}

\begin{abstract}
The purpose of this study was to compare the effects of six weeks of squat training with those of plyometric training upon different types of physical performance in adolescent male and female team handball players. Twenty-six adolescent male and female team handball players (age $13.8 \pm 0.5 \mathrm{yr}$, body mass $57.5 \pm 11.5 \mathrm{~kg}$, body height $1.70 \pm 0.10 \mathrm{~m}$ ) participated in the study. Half of the subjects $(n=13)$ conducted a squat training program, while the other half conducted a plyometric training program, twice a week for six weeks, in addition to their normal team handball practice. Both groups increased their performance after six weeks in agility, $30 \mathrm{~m}$ sprint and Yo-Yo IR1 tests, while no changes were found in the CMJ, strength test and throwing velocity. The results suggest that either a short in-season 6-week squat orplyometric training regimen can improve the physical performance of the lower body, while these programs will not enhance the performance of the upper body.
\end{abstract}

Keywords: CMJ; throwing; agility; Yo-Yo IR1; sprint

\section{INTRODUCTION}

Ball sports like basketball, soccer and team handball are very popular sports in the world that includes a lot of different movements requiring sprinting, agility, power, strength and aerobic fitness $[13,16]$. There are a lot of ways 
to improve these motor abilities, but resistance training with free weights has been shown to be positive for power/jumping [21] and throwing [8]. However, several weight training programs had ambiguous results upon sprinting, repeated sprinting, agility and aerobic fitness performance [22]. Theoretically, the purpose of weight training is to increase the strength of the muscles, thereby changing the force-velocity relationship [10]. By increasing the strength of the muscles, it is plausible to increase the performance in sprinting, jumping and throwing due to increased maximal force, which would make it easier to throw, jump or sprint with the same absolute weight after training. However, in weight training, the execution velocity of the movements is much lower than in regular throwing, jumping and sprint movements. Furthermore, Kristiansen et al. [12] found that training resistance with lower velocity did not have a positive transfer to higher velocities. The training effect of movementsis often related to the specific execution in the performance context.

Plyometric or also called jump training is also often used in team handball, it is based upon increasing the rate of force development and stretch shortening cycles during the different movements [3]. Plyometric training is more explosive than weight training and would be easier to transfer into the different actions in team handball, such as jumping and sprinting. However, in most studies on plyometric, training with only one (depth jumps) or two countermovement jump (CMJ) plyometric exercises is used, with very high intensity $[4,19]$. This could perhaps influence the injury rate and the motivation of the involved subjects. However, an integrated short plyometric training program with several small jump exercises, resulting in increased variation, could have the same or a better effect. This could also increase the motivation of the subjects. Marques et al. [14] showed that the use of a short plyometric training program (consisting of four exercises every time) that is integrated intoregular soccer training had positive results upon sprinting times $(+3.2 \%)$, jumping $(+7.7 \%)$ and kicking velocity $(6.6 \%)$ in adolescent soccer players.

However, to our best knowledge, no study has investigated the effects of power training with weights (2-legged squats), compared with plyometric training, on jumping, sprinting, agility, aerobic fitness and throwing performance in adolescent team handball players. Earlier studies in soccer players showed increased physical performance $[14,15]$, but team handball is a different type of ball sport. Difference in outcome could be the result of the demands of the different ball sports. Therefore, the purpose of the present study was to investigate the effects of these two training regimes over a 
period of six weeks in adolescent team handball players. It was hypothesized that both groups would enhance their sprinting, jumping and agility performance, as was found in the studies of Marques et al. [14, 15] on soccer players, which used the same training programs. In addition, it was expected that throwing performance and aerobic fitness would not increase, due to the fact that they werenot subject to extra training. Furthermore, it was expected that the performance of the plyometric training group would increase more than that of the 2-legged squat training group, because plyometric training is much more explosive in nature, and it simulates the movements that are tested.

\section{MATERIAL AND METHODS}

\section{Participants}

Twenty-six competitive male and female adolescent team handball players (age $13.8 \pm 0.5 \mathrm{yr}$, body mass $57.5 \pm 11.5 \mathrm{~kg}$, body height $1.70 \pm 0.10 \mathrm{~m}$ ) participated in the study. The participants were from two different teams (one male and one female team) playing at the national level in their age class. The subjects were fully informed about the protocol before the start of the study. Informed consent was obtained prior to testing from all subjects and parents, in approval with the recommendations of the local ethical committee and current ethical standards in sports and exercise research. The experiment was conducted near the end of the competition season, from February to April. The tests were always conducted on the same day of the week and at the same time of the day (17:00-20:00 h) with the same researchers at each performance test.

\section{Procedures}

After a standardised general warm-up of $10 \mathrm{~min}$, each participant was tested randomly using five tests: 1 ) for explosive strength of lower limbs, by a CMJ and a CMJ with arm swing. In the CMJ, the participants started from a standing position with their hands on their waist and a linear encoder (ETEnc-02, Ergotest Technology AS, Langesund, Norway) around their waist. Then, they flexed their knees to $90^{\circ}$, followed by a jump as high as possible while holding their hands on their waist. In the CMJ with arm swing, the participants were allowed to use their arms in the jump movement. The distance from the standing position to the highest position measured with the linear encoder was measured as the jumping height. Three attempts in 
each condition were made, with a half minute of rest between each attempt. 2) Sprint performance was tested by three maximum effort sprints of $30 \mathrm{~m}$, for which the time was measured each $5 \mathrm{~m}$ using Brower equipment (Wireless Sprint System, USA). They started $0.3 \mathrm{~m}$ behind the first beams, which were placed at a $0.8 \mathrm{~m}$ height. The subjects performed sprints, separated by 3 min of rest. Only the best attempt was considered. 3) Agility was tested by an agility test proposed by Mohamed et al. [16]. The agility test showed maximal movement in a specific pattern related to team handball movements in defence (moving forwards, sideways and backwards), measuring the time in seconds (Figure 1), in which the participants had to touch each cone (height: $0.3 \mathrm{~m}$ ). 4) Throwing performance was evaluated in two conditions: 1$\}$ a standing throw from $7 \mathrm{~m}$ and 2$\}$ throwing with three preliminary steps from $7 \mathrm{~m}$ distance to the goal. The participants were instructed to throw a regular team handball ball (men: weight approximately $0.45 \mathrm{~kg}$, circumference $0.59 \mathrm{~m}$; women: weight approximately $0.35 \mathrm{~kg}$, circumference $0.56 \mathrm{~m}$ ) as hard as possible straight forward. The maximal ball velocity was determined using a Doppler radar gun (Sports Radar 3300, Sports Electronics Inc.), with $\pm 0.028 \mathrm{~m} / \mathrm{s}$ accuracy within a field of 10 degrees from the gun. The radar gun was located $1 \mathrm{~m}$ behind the subject at ball height during the throw. In every test, three attempts were made, and the best attempt was recorded. 5) Lower limb strength was tested in two-legged squats with a weight of 20,30 and $40 \mathrm{~kg}$. Three repetitions per weight were conducted. The mean propulsion velocity at each weight [11] was calculated with a linear encoder with a resolution of $1000 \mathrm{~Hz}$ (T-force, Murcia, Spain) to establish, by linear regression, the training weight at approximately $1 \mathrm{~m} / \mathrm{s}$. This was chosen because this velocity has been observed to be the optimal one to produce the maximal power output [10].

Aerobic fitness was tested at the end of all other tests by conducting the Yo-Yo Intermittent Recovery Test level 1 (Yo-Yo IR1), according to the procedures suggested by Bangsbo et al. [2]. The Yo-Yo IR1 was used because it has been shown to be an accurate test to evaluate an individual's ability to repeatedly perform intense exercise, and it simulates typical performance in team handball matches, like a fast break with return with increasing speed during a team handball season $[7,14]$.

The subjects were tested three times: pre-test, retest and post-test. The retest was exactly one week after the pre test to avoid a learning effect of the tests. After the retest, the subjects from both teams were matched on their throwing performance and were allocated to eithera plyometric training adapted from an earlier study by Marques et al. [14] (4 different types 
of jumps, 156-195 jumps per session, Table 1) or a squat training group in which the participants had to conduct 3 series of 6 repetitions, at around $1 \mathrm{~m} / \mathrm{s}$ mean propulsion velocity. This weight corresponds with approximately $40-45 \%$ of 1 RM [8].

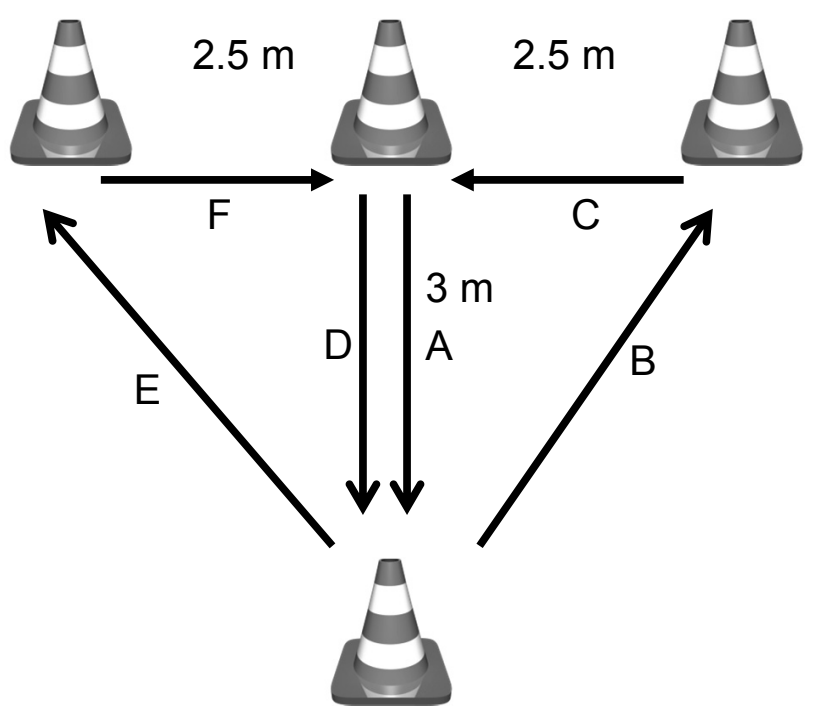

Figure 1. Schematic representation of the agility test adapted from Mohamed et al. (2009)

Table 1. Training program with the total repetitions per time for A) plyometric training group and B) strength training group

\begin{tabular}{lcccccc}
\hline A) & \multicolumn{6}{c}{ Training session } \\
\hline Exercise & $\mathbf{1}$ & $\mathbf{2}$ & $\mathbf{3}$ & $\mathbf{4}$ & $\mathbf{5}$ & $\mathbf{6}$ \\
\hline $\begin{array}{l}\text { 2 legged jumps } \\
\text { (without bending } \\
\text { knees) }\end{array}$ & $3 \times 20$ & $3 \times 20$ & $3 \times 20$ & $3 \times 25$ & $3 \times 25$ & $3 \times 25$ \\
\hline $\begin{array}{l}2 \text { legged jumps } \\
\text { (with bending knees) }\end{array}$ & $3 \times 10$ & $3 \times 10$ & $3 \times 10$ & $3 \times 10$ & $4 \times 10$ & $4 \times 10$ \\
\hline $\begin{array}{l}\text { Hop with one leg } \\
\text { short and quickly }\end{array}$ & $3 \times 10$ & $3 \times 10$ & $3 \times 10$ & $3 \times 10$ & $2 \times 10$ & $2 \times 10$ \\
\hline $\begin{array}{l}\text { 1-legged jumps as } \\
\text { high as possible }\end{array}$ & $2 \times 8$ & $2 \times 8$ & $2 \times 8$ & $2 \times 8$ & $3 \times 8$ & $3 \times 8$ \\
\hline $\begin{array}{l}\text { Sprint from standing } \\
\text { Sprint from lying start }\end{array}$ & $5 \times 20 \mathrm{~m}$ & $6 \times 20 \mathrm{~m}$ & $6 \times 20 \mathrm{~m}$ & $6 \times 20 \mathrm{~m}$ & $2 \times 4 \times 20 \mathrm{~m}$ & - \\
\hline $\begin{array}{l}\text { Sprition } \\
\text { position }\end{array}$ & & & & & & $2 \times 4 \times 10 \mathrm{~m}$
\end{tabular}


Table 1. Continuation

\begin{tabular}{|c|c|c|c|c|c|c|}
\hline \multirow[b]{2}{*}{ Exercise } & \multicolumn{6}{|c|}{ Training session } \\
\hline & 7 & 8 & 9 & 10 & 11 & 12 \\
\hline $\begin{array}{l}2 \text { legged jumps } \\
\text { (without bending } \\
\text { knees) }\end{array}$ & $3 \times 30$ & $3 \times 30$ & $4 \times 20$ & $4 \times 20$ & $5 \times 20$ & $5 \times 20$ \\
\hline $\begin{array}{l}2 \text { legged jumps as } \\
\text { far as possible (with } \\
\text { bending knees }\end{array}$ & $3 \times 10$ & $3 \times 10$ & $4 \times 10$ & $4 \times 10$ & $4 \times 10$ & $4 \times 10$ \\
\hline $\begin{array}{l}\text { Hop with one leg } \\
\text { short and quickly }\end{array}$ & $3 \times 10$ & $3 \times 10$ & $3 \times 10$ & $3 \times 10$ & $3 \times 10$ & $3 \times 10$ \\
\hline $\begin{array}{l}\text { 1-legged jumps as } \\
\text { high as possible }\end{array}$ & $3 \times 10$ & $3 \times 10$ & - & - & - & - \\
\hline $\begin{array}{l}\text { Jump shot without } \\
\text { ball }\end{array}$ & - & - & $3 \times 5$ & $3 \times 5$ & $3 \times 5$ & $3 \times 5$ \\
\hline $\begin{array}{l}\text { Sprint from lying start } \\
\text { position }\end{array}$ & $5 \times 30 \mathrm{~m}$ & $5 \times 15 \mathrm{~m}$ & - & - & - & - \\
\hline $\begin{array}{l}\text { Sprint from } 5 \mathrm{~m} \\
\text { sideways start }\end{array}$ & - & - & $6 \times 30 \mathrm{~m}$ & $6 \times 15 \mathrm{~m}$ & $2 \times 4 \times 30 \mathrm{~m}$ & $2 \times 4 \times 15 \mathrm{~m}$ \\
\hline
\end{tabular}

\begin{tabular}{|c|c|c|c|c|c|c|}
\hline \multirow{2}{*}{$\begin{array}{l}\text { B) } \\
\text { Exercise }\end{array}$} & \multicolumn{6}{|c|}{ Training session } \\
\hline & 1 & 2 & 3 & 4 & 5 & 6 \\
\hline Squats & $3 \times 6$ & $3 \times 6$ & $3 \times 6$ & $3 \times 6$ & $3 \times 6+2.5 \mathrm{~kg}$ & $3 \times 6+2.5 \mathrm{~kg}$ \\
\hline $\begin{array}{l}\text { Sprint from } \\
\text { standing start } \\
\text { position }\end{array}$ & $5 \times 20 \mathrm{~m}$ & $6 \times 20 \mathrm{~m}$ & $6 \times 20 \mathrm{~m}$ & $6 \times 20 \mathrm{~m}$ & $2 \times 4 \times 20 \mathrm{~m}$ & - \\
\hline \multirow[t]{2}{*}{$\begin{array}{l}\text { Sprint from lying } \\
\text { start position }\end{array}$} & & & & & & $2 \times 4 \times 10 \mathrm{~m}$ \\
\hline & \multicolumn{6}{|c|}{ Training session } \\
\hline Exercise & 7 & 8 & 9 & 10 & 11 & 12 \\
\hline Squat & $\begin{array}{c}3 \times 6+ \\
5 \mathrm{~kg}\end{array}$ & $\begin{array}{c}3 \times 6+ \\
5 \mathrm{~kg}\end{array}$ & $\begin{array}{l}3 \times 6+ \\
7.5 \mathrm{~kg}\end{array}$ & $\begin{array}{l}3 \times 6+ \\
7.5 \mathrm{~kg}\end{array}$ & $\begin{array}{c}3 \times 6+ \\
5 \mathrm{~kg}\end{array}$ & $\begin{array}{l}3 \times 6+ \\
2.5 \mathrm{~kg}\end{array}$ \\
\hline $\begin{array}{l}\text { Sprint from lying } \\
\text { start position }\end{array}$ & $5 \times 30 \mathrm{~m}$ & $5 \times 15 \mathrm{~m}$ & - & - & - & - \\
\hline $\begin{array}{l}\text { Sprint from } 5 \mathrm{~m} \\
\text { sideways start }\end{array}$ & - & - & $6 \times 30 \mathrm{~m}$ & $6 \times 15 \mathrm{~m}$ & $2 \times 4 \times 30 \mathrm{~m}$ & $2 \times 4 \times 15 \mathrm{~m}$ \\
\hline
\end{tabular}

The training weight was increased after several training sessions, according to the overload principle (Table 2). Both groups conducted two training sessions per week for a period of 6 weeks, and the training was integrated intothe beginning of their regular team handball training sessions. Both groups conducted the same regular training sessions and the only difference between the groups was the plyometric and squat training sessions. 
Table 2. Mean $( \pm S D)$ anthropometrics and performance in the different tests of the strength and jump training groups at the pre-test

\begin{tabular}{lcc}
\hline Group & Strength training & Plyometric training \\
\hline Body Mass $(\mathrm{kg})$ & $53.2 \pm 7.2$ & $61.5 \pm 13.5$ \\
\hline Height $(\mathrm{m})$ & $1.67 \pm 0.09$ & $1.72 \pm 0.10$ \\
\hline Age $(\mathrm{yr})$ & $13.7 \pm 0.5$ & $13.9 \pm 0.5$ \\
\hline $30 \mathrm{~m}$ Sprint $(\mathrm{s})$ & $5.09 \pm 0.37$ & $5.20 \pm 0.40$ \\
\hline Agility $(\mathrm{s})$ & $6.78 \pm 0.67$ & $6.53 \pm 0.75$ \\
\hline Standing $7 \mathrm{~m}$ throw $(\mathrm{m} / \mathrm{s})$ & $17.0 \pm 1.2$ & $18.3 \pm 2.9$ \\
\hline Running throw $(\mathrm{m} / \mathrm{s})$ & $18.3 \pm 1.2$ & $19.7 \pm 3.0$ \\
\hline 1 m/s squat weight $(\mathrm{kg})$ & $19.9 \pm 11.2$ & $24.4 \pm 14.9$ \\
\hline CMJ (cm) & $35.1 \pm 5.3$ & $36.3 \pm 6.4$ \\
\hline CMJ arm swing $(\mathrm{cm})$ & $40.5 \pm 6.0$ & $44.5 \pm 7.4$ \\
\hline Yo-Yo IR 1 (m) & $843 \pm 370$ & $791 \pm 410$ \\
\hline
\end{tabular}

No significant differences between both groups at none of the parameters at the pretest

\section{Statistical analysis}

A one-way ANOVA was performed on the anthropometrics and different physical performance tests (sprinting, strength, aerobic fitness, jumps, throws and agility) of the two groups at the pre-test. To compare the effects of the training protocols, a mixed design 2 (test occasion: pre-post: repeated measures) $\times 2$ (group: strength vs. plyometric) analysis of variance (ANOVA) was used. Furthermore, the absolute and percentage change from the pre- to post-test, for each performance test, was also calculated for a comparison of the change between the two groups and a comparison with other studies. The effect size was evaluated with $\eta^{2}$ (Eta partial squared), where $0.01<\eta^{2}<0.06$ constitutes a small effect, a medium effect when $0.06<\eta^{2}<0.14$ and a large effect when $\eta^{2}>0.14$ [5]. The reliability of the performance tests was evaluated by calculating the test-retest reliability. The re-test was performed one week after the pre-test, on the same day of the week and at the same time of the day in the same order of tests for each participant. The level of significance was set at $\mathrm{p} \leq 0.05$. The statistical analysis was performed using SPSS version 19.0 (SPSS, Inc., Chicago, IL). 


\section{RESULTS}

Pre-test data indicated no significant differences in anthropometrics $(\mathrm{p} \geq 0.071)$ and performance tests $(\mathrm{p} \geq 0.148)$ between the two groups (Table 2). The test-retest correlations for the different performance tests were all over 0.9 , indicating a high reliability.

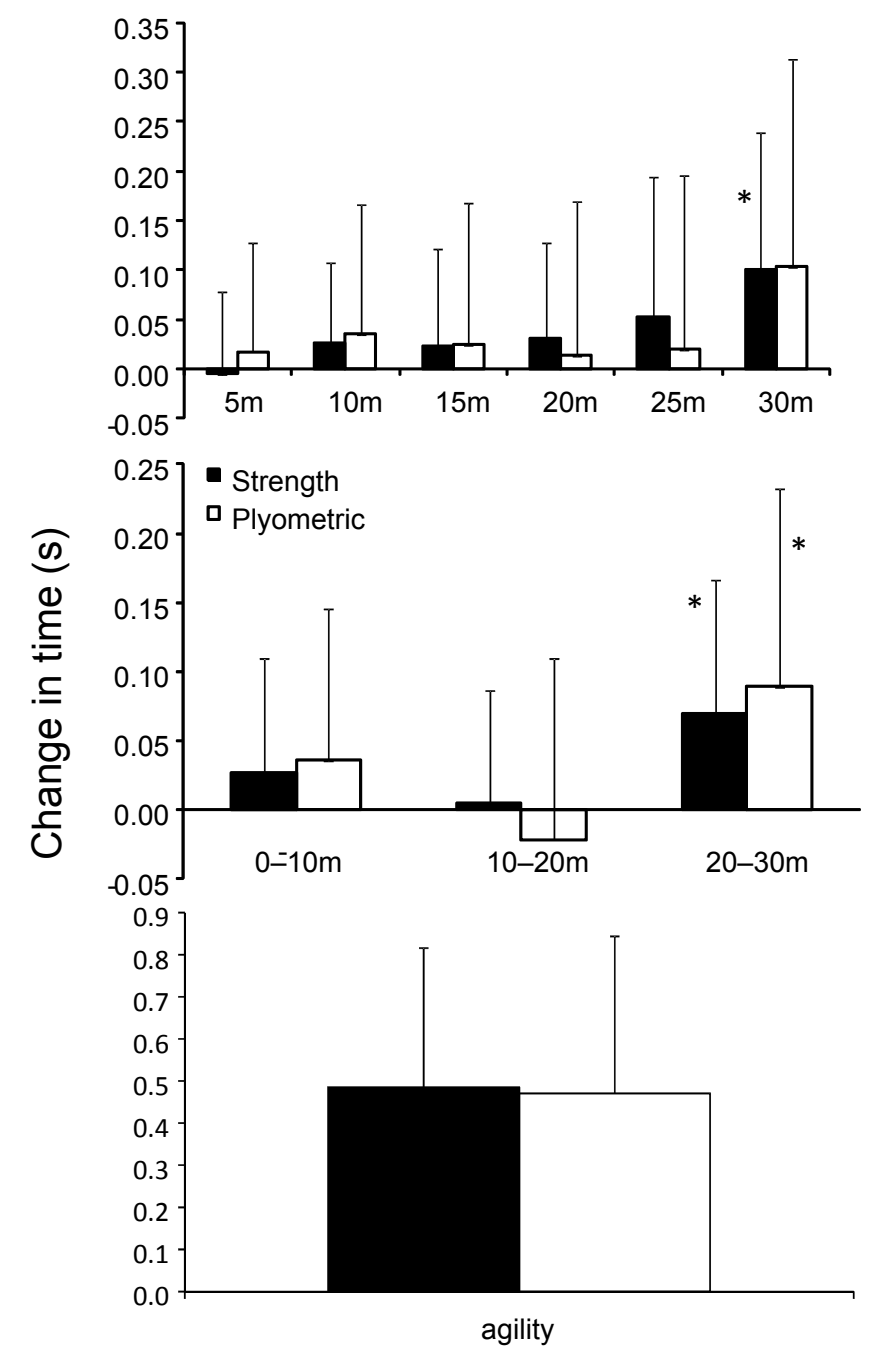

Figure 2. Change in performance in sprinting for each 5 meters, sprint from 0-10 $\mathrm{m}$, $10-20 \mathrm{~m}$ and $20-30 \mathrm{~m}$ and for agility (Mean \pm SD) from pre- to post-test for the strength training and plyometric training groups

* indicates a significant difference $(p<0.05)$ in the change of time from the pre- to the post-test in this group 


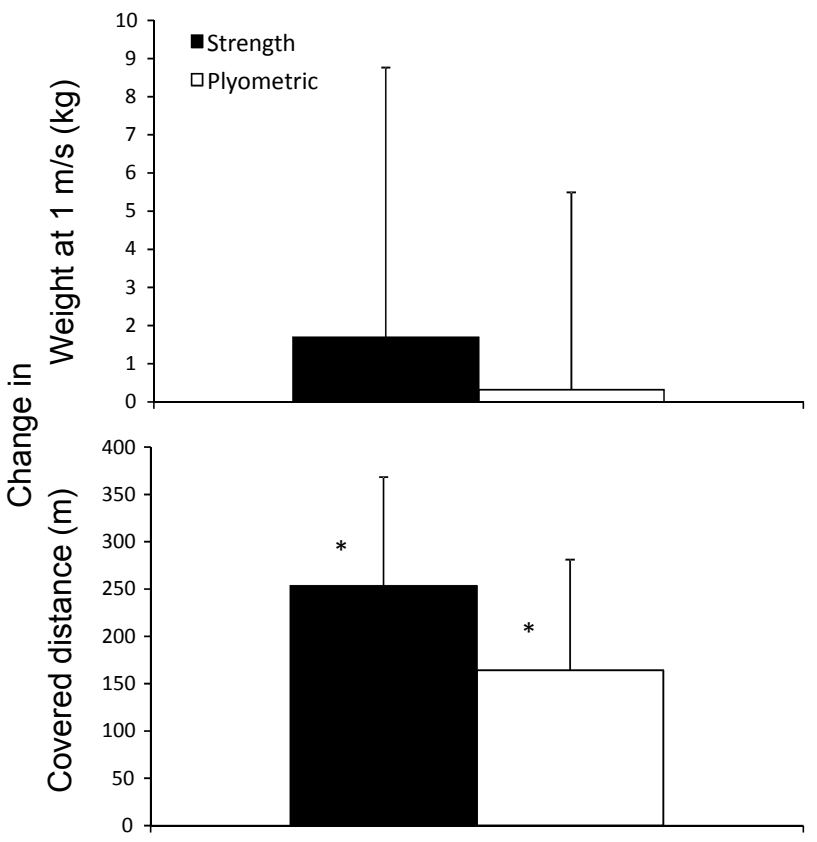

Figure 3. Change in performance in weight at $1 \mathrm{~m} / \mathrm{s}$ and distance covered in the Yo-Yo IR1 test (Mean $\pm \mathrm{SD}$ ) from pre- to post-test for the strength training and plyometric training groups

* indicates a significant difference $(p<0.05)$ in the change in performance from the pre- to the post-test in this group

A significant main effect from pre- to post-test was found (+2.0\%) for sprint performance over $30 \mathrm{~m}\left(\mathrm{~F}=15.1, \mathrm{p}=0.001, \mathrm{~h}^{2}=0.397\right)$ and agility times $(+7.6 \%$, $\mathrm{F}=98.6, \mathrm{p}<0.001, \mathrm{~h}^{2}=0.81$, Figure 2$)$. However, the change in performance was only significant at $30 \mathrm{~m}$ and for the time from 20 to $30 \mathrm{~m}(\mathrm{~F}=24.8$, $\mathrm{p}<0.001, \mathrm{~h}^{2}=0.52$, Figure 2). At the other distances, no significant changes were observed $\left(\mathrm{F} \leq 1.97, \mathrm{p} \geq .017, \mathrm{~h}^{2}=0.079\right.$, Figure 2$)$. Also, the running distance in the Yo-Yo IR1 test $(+27.3 \%)$ was significantly increased after six weeks $\left(\mathrm{F}=51, \mathrm{p}<0.001, \mathrm{~h}^{2}=0.73\right.$, Figure 3$)$. No significant change in the weight, at $1 \mathrm{~m} / \mathrm{s}$, in the strength test $\left(+3.8 \% ; \mathrm{F}=0.66, \mathrm{p}=0.42, \mathrm{~h}^{2}=0.03\right.$, Figure 3), jumping height was observed for the countermovement jumps, with $(+0.5 \%)$ or without arm $(+1.6 \%)$ swing $\left(\mathrm{F} \leq 0.97, \mathrm{p} \geq 0.34, \mathrm{~h}^{2} \geq 0.04\right.$, Figure 4 ) and peak ball velocity (standing $7 \mathrm{~m}$ throw: $-0.1 \%$, running $7 \mathrm{~m}$ throw: $-1.0 \%)$ in the throwing tests ( $\mathrm{F} \leq 1.23, \mathrm{p} \geq 0.279, \mathrm{~h}^{2} \geq 0.05$, Figure 4$)$ were found.

No significant differences in the changes between the two training groups were found $(\mathrm{p} \geq 0.31)$. 


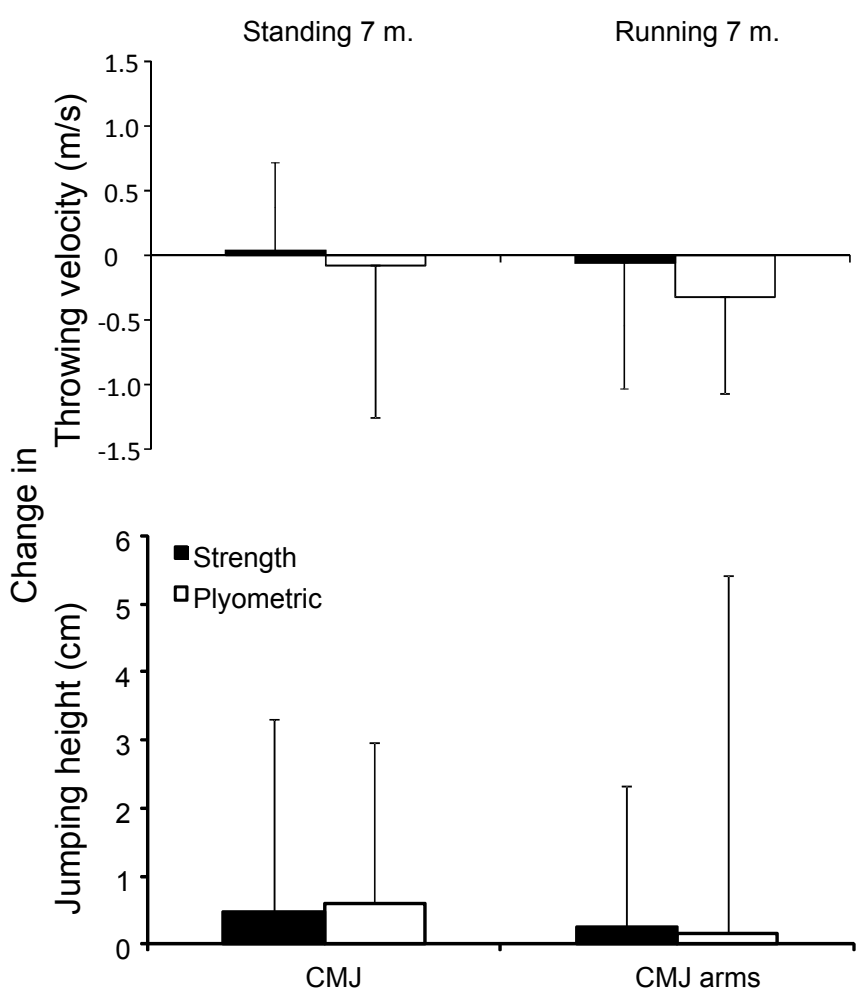

Figure 4. Change in performance of maximal ball velocity in the standing $7 \mathrm{~m}$ throw and the $7 \mathrm{~m}$ throw with 3 preliminary steps, jumping height for the countermovement jump, with and without arm swing (Mean $\pm S D$ ), from pre- to post-test for the strength training and plyometric training groups

* indicates a significant difference $(p<0.05)$ in the change in performance from the pre- to the post-test in this group

\section{DISCUSSION}

The purpose of our study was to compare the effects of adding a plyometric training program with a weight training program to the normal in-season regimen on different performance tests in adolescent team handball players. The main findings were that sprint, agility, and aerobic fitness increased, while there were no differences in jumping height, strength and peak ball velocity in throwing, with no differences in the changes between the two groups after the training period.

The increases in performance in sprinting were in line with earlier similar studies on soccer players $[14,15]$. We found that the performance changes in the $30 \mathrm{~m}$ sprint primarily happened in the last 5-10 $\mathrm{m}$ (Figure 2). The performance increased by around $5.3 \%$, which was similar to the squat 
training group $(+2.5 \%)$ in the other study conducted by Marques et al. [15] and in the plyometric study ( $+3 \%)$ conducted by Marques et al. [14]. In the latter study, they also showed that there was only an increase in performance over the last $10 \mathrm{~m}$, when the same plyometric program was applied to adolescent soccer players.

The strength weight at $1 \mathrm{~m} / \mathrm{s}$ increased similarly (although not significantly) in the present study for the strength training group as in the study conducted by Marques et al. [15] (6 vs 9\%), which indicates that using the same training regime by different training groups, but same squat training experience (sports students vs adolescent team handball players) gives the same results. It was not surprising that the throwing velocity did not change, because the subjects did not train extra for this, and they were near the end of the season. It was surprising that the jumping height did not increase, because an earlier study that used the same training program in young soccer players showed increased (+7.7\%) jumping performance [14]. This may be explained by the fact that team handball players already do a great deal of trainingin jumping during their regular training, compared to soccer players. The increased number of jumps would not make a big difference in total for the team handball players, and therefore, would not substantially increase their jumping height during the tests. In addition was the focus of most jumps in the training program upon velocity of movement (Table 1) to increase leg stiffness and not on jumping height, which was tested by the vertical jump test.

Aerobic fitness was also increased after the training period, which was surprising, because the subjects did not train specifically for aerobic fitness. A possible reason for the increase may be due to the aerobic fitness test that was conducted: the Yo-Yo IR1 test. In this test, the players have to run $40 \mathrm{~m}$, with a turn at $20 \mathrm{~m}$, which requires deceleration and acceleration in the legs during the turn. It is designed to evaluate an individual's ability to repeatedly perform intense exercise, which is very typical for team handball [1]. This requires explosive strength. In both training groups, the explosive strength was stimulated, which was shown by the increases in the other performance tests. The test performance of the Yo-Yo IR1, which covered distances in our study, was comparable with studies performed upon youth national teams in soccer [1], which showed that our subjects were at a high level for their age.

A limitation of our study was that we did not use a control group to investigate the training effects. However, in earlier studies with the same training programs involving soccer players of the same age [14, 15], it was shown that the control group did not gain enhanced motor abilities. In 
addition, the tests and training were conducted at the end of the competition season, in which it is normal for performance levels to decrease [6] and not to increase, as shown in our study. Furthermore, it is also ethically difficult to divide a regular training group in two: one experimental group and one control group, in which the control group is not allowed to train at the beginning of the training. Therefore, only two training groups were included, without a control group.

No differences in enhancement were found between the groups; this was not hypothesized, because it was expected that the performance of the plyometric training group would show more enhancement in the different performance tests. An explanation for this finding could be that the weight training group squatted with relatively small weights ( $45-50 \%$ of $1 \mathrm{RM})$ with full effort. This is also called power training [11], which, in other studies, showed good results in strength enhancement. In addition, the power training was combined with some sprinting, which could have a positive transfer from enhanced strength to sprinting. This training was also combined with the players' regular training, and the players started with either the strength or plyometric training before conducting the rest of their regular training. The effects of including these training programs at the start of the regular training could have a post-activation potentiation effect (PAP) on the rest of the training, which could increase performance in the rest of the training [20]. Thereby, the training effect on the other performance tests, like the agility and Yo-Yo IR1 tests, could have been influenced positively. Both training groups had never trained so hard at the start of their regular training. This could have caused new metabolic stress and mechanical drag that may have led to positive performance effects for the rest of the training. More studies that investigate the acute effect of these two types of training should be performed before we can state whether the regular training is also affected by these types of training.

In future studies, the effects of gender, training order and time of the year should be included to investigate whether they affect the performance of these training programs. It is possible that the effects are different between genders or that the time of the year has an influence. In our study, the training groups were too small to make an appropriate comparison of the effects between genders.

It was indicated in our study that 6 weeks of supplementary plyometric or weight training (2-legged squats) in adolescent team handball players at the end of the competition season can enhance performance in, sprinting, agility and aerobic fitness, while it did not enhance jump heights, 
leg strength or throwing. It seems that training with 2-legged squats with weights of $45-50 \%$ of $1 \mathrm{RM}$ (power training) or plyometric have the same effect on performance, and that they both could be included in regular training sessions for adolescent team handball players.

\section{REFERENCES}

1. Bangsbo J, Iaia FM, Krustrup P. (2008) The Yo-Yo intermittend recovery test: a useful tool for evaluation of physical performance in intermittent sports. Sports Med, 38: 37-51

2. Bangsbo JL, Nørregaard, Thorsø F. (1991) Activity profile of competition soccer. Can J Sport Sci, 16: 110-116

3. Bobbert MF. (1990) Drop jumping as a training method for jumping ability. Sports Med, 9: 7-22

4. Campillo R, Andrade DC, Izquierdo M. (2013) Effects of plyometric training volume and training surface on explosive strength. J Strength Cond Res, 27 (10): 2714-2722

5. Cohen J. (1988) Statistical Power Analysis for the Behavioral Sciences, 2nd ed. Hillsdale, New Jersey: Lawrence Erlbaum Associates

6. Granados C, Izquierdo M, Ibanez J, Ruesta M, Gorostiaga EM. (2008) Effects of an entire season on physical fitness in elite female handball players. Med Sci Sports Exerc, 40: 351-361

7. Hermassi S, Aouadi K, Khlifa R, van den Tillaar R, Shepard R, Chelly M. (2015) Relationships between the Yo-Yo intermittent recovery test and anaerobic performance tests in adolescent handball players. J Hum Kinet, 42: 197-205

8. Hoff J, Almåsbakk B. (1995) The effect of maximum strength training on throwing velocity and muscle strength in female team-handball players. J Strength Cond Res, 9: 255-258

9. Izquierdo M, Hakkinen K, Gonzalez-Badillo JJ, Ibanez J, Gorostiaga EM. (2002) Effects of long-term training specificity on maximal strength and power of the upper and lower extremities in athletes from different sports. Eur J of Appl Physiol, 87: 264-271

10. Kaneko M, Fuchimoto T, Toji H, Suei K. (1983) Training effect of different loads on the force-velocity relationship and mechanical power output in human muscle. Scand J Sports Sci, 5: 50-55

11. Knuttgen HG, Komi PV. (1992) Basic definitions for exercise. In: Komi PV (ed). Strength and Power in Sport. Oxford: Blackwell Scientific Publications, 3-6

12. Kristensen GO, van den Tillaar R, Ettema G. (2006) Velocity specificity in early phase sprint training. J Strength Cond Res, 20: 833-837

13. Lidor R, Argov E, Daniel S. (1998) An exploratory study of perceptual motor abilities of women: novice and skilled players of team handball. Percept Mot Skills, 86: 279-288 
14. Marques MC, Pereira A, Reis IG, van den Tillaar R. (2013) Does an in-season 6-week of a combined sprint and jump training regimen improve upon the lower body performance in young competitive soccer players? J Hum Kin, 39: 157-166

15. Marques, MC, van den Tillaar R, Sanchéz-Medina L, Marinho D, Izquierdo M. (2015) Impact of short and low frequency training period of combined strength training approaches on sprint performance. Int J Sports Med, 36: 1-7

16. Mohamed H, Vaeyens R, Matthys S, Multail M, Lefevre J, Lenoir M, Philppaerts R. (2009) Anthropometric and performance measures for the development of a talent detection and identification model in youth handball. J Sport Sci, 27: 257-266

17. Sanchez-Medina L, Gonzalez-Badillo J. (2011) Velocityloss as an indicator of neuromuscular fatigue duringresistance training. Med Sci Sports Exerc, 43: $1725-1734$

18. Sæterbakken AH, Fimland MS. (2013) Muscle force output and electromyographic activity in squats with various unstable surfaces. J Strength Cond Res, 27: $130-136$

19. Sáez de Villarreal E, Requena B, Izquierdo M, Gonzalez-Badillo JJ. (2013) Enhancing sprint and strength performance: combined versus maximal power, traditional heavy-resistance and plyometric training. J Sci Med Sport, 16: 146150

20. Tillin NA, Bishop D. (2009) Factors modulating post-activation potentiation and its effect on performance of subsequent explosive activities. Sports Med, 39: $147-166$

21. Tsimahidis K, Galazoulas C, Skoufas D, Papaiakovou G, Bassa E, Patikas D, Kotzamanidis C. (2010) The effect of sprinting after each set of heavy resistance training on the running speed and jumping performance of young basketball players. J Strength Cond Res, 24: 2102-2108

22. Yamamoto LM, Lopez RM, Klau JF, Casa J, Kreamer WJ, Maresh CM. (2008) The effects of resistance training on endurance distance running performance among highly trained runners: a systematic review. J Strength Cond Res, 22 (6): 2036-2035

\section{Correspondence to:}

Roland van den Tillaar PhD

Department of Sports Science

Nord Trøndelag University College

Odins veg 23, 7603 Levanger, Norway

E-mail: roland.tillaar@hint.no

Tel: +47-5767-1883

Fax: +47-7411-2001 